\title{
PDCD6 is an independent predictor of progression free survival in epithelial ovarian cancer
}

Dan $\mathrm{Su}^{1,2}$, Haiyan Xu², Jianguo Feng ${ }^{2}$, Yun Gao ${ }^{2}$, Linhui $\mathrm{Gu}^{2}$, Lisha Ying ${ }^{2}$, Dionyssios Katsaros ${ }^{3}$, Herbert Yu ${ }^{4}$, Shenhua $\mathrm{Xu}^{2^{*}}$ and Ming Qi ${ }^{1,5^{*}}$

\begin{abstract}
Background: Programmed cell death 6 (PDCD6) beside its known proapoptotic functions may be a player in survival pathways in cancer. The purpose of this study is to further explore the roles of PDCD6 in epithelial ovarian cancer.

Methods: Lentiviral vector with shRNA for PDCD6 was used to investigate the effects of PDCD6 knockdown on cell growth, cell cycle, apoptosis and motility in ovarian cancer cells. Two hundred twelve epithelial ovarian cancer tissues were analyzed for mRNA expression of PDCD6 using RT-PCR. Associations of its expression with clinical pathological factors, progression free and overall survival were evaluated.

Results: PDCD6 is highly expressed in metastatic ovarian cancer cells and positively regulates cell migration and invasion. Significantly, the level of PDCD6 expression in epithelial ovarian cancer correlates with clinical progression. Patients with medium or high levels of PDCD6 mRNA were at higher risk for disease progression, compared to those with low levels ( $H R, 1.29 ; P=0.024$ for medium levels; and $H R, 1.57 ; P=0.045$ for high levels) after adjusting for age, disease stage, tumor grade, histologic type and residual tumor size. Kaplan-Meier survival analysis demonstrated similar results. However, no association was found between PDCD6 expression and overall survival.

Conclusions: PDCD6 seems to play an important role in ovarian cancer progression and it may be an independent predictor of progression free survival in epithelial ovarian cancer. Further studies are needed to more completely elucidate the molecular mechanisms of PDCD6 involve in ovarian cancer progression.
\end{abstract}

\section{Background}

Ovarian cancer is a common gynecologic malignancy and a major cause of cancer death among women in the United States [1]. The 5-year survival rate for patients with ovarian cancer is only $35 \%[2,3]$. The high mortality of ovarian cancer is related to our inability to detect the disease early and to treat it effectively. Most of ovarian cancer patients ultimately die from tumor recurrence and metastasis, despite the fact that they initially respond to the treatment of cytoreductive surgery followed by paclitaxel and platinum-based chemotherapy.

\footnotetext{
* Correspondence: shenhuaxu@hotmail.com; mingqi.zj@gmail.com ${ }^{1}$ Center for Genetic and Genomic Medicine, School of Medicine, Zhejiang University, Hangzhou, Zhejiang, China

${ }^{2}$ Cancer Research Institute, Zhejiang Cancer Hospital, Hangzhou, Zhejiang, China

Full list of author information is available at the end of the article
}

So, understanding the molecular mechanisms involving the initiation, progression, and metastasis of ovarian cancer is important for the prevention, detection, and treatment of ovarian cancer.

In our previous study, two epithelia ovarian cancer cell lines with low and high metastatic potentials were set up successively, named as HO-8910, and HO-8910 PM respectively $[4,5]$. Seventeen different significantly expressed proteins between them were detected by comparative proteomic analysis, of which programmed cell death 6 (PDCD6), also named as apoptosis-linked gene 2 (ALG-2), was identified [6].

PDCD6, a calcium-binding protein belonging to the penta-EF-hand protein family, participates in $\mathrm{T}$ cell receptor-, Fas-, and glucocorticoid-induced programmed cell death $[7,8]$. However, apoptosis was not blocked in

\section{Biomed Central}


mice deficient for PDCD6, suggesting PDCD6 is functionally redundant [9]. Furthermore, PDCD6 was found up-regulated in lung cancer and hepatoma tissue compared with normal tissue, also suggesting that PDCD6 beside its known proapoptotic functions may be a player in survival pathways [10]. Similarly, our previous results showed PDCD6 was over-expressed in HO-8910 PM which has higher metastatic potential, as compared with HO-8910 [6]. To further explore the function of PDCD6 in ovarian cancer, in this study, we investigated the effects of PDCD6 knockdown by short hairpin RNA (shRNA) on cell growth, cell cycle, apoptosis and motility of ovarian cancer cells. In addition, we analyzed the association between PDCD6 expression, clinical pathological factors and outcome in ovarian cancer patients.

\section{Materials and methods Cell culture}

HO-8910 and HO-8910 PM cells were established by Zhejiang Cancer Hospital $[4,5]$. The cells were cultured in RPMI-1640 medium containing 10\% newborn bovine serum, supplemented with $100 \mathrm{U} / \mathrm{ml}$ penicillin and 125 $\mu \mathrm{g} / \mathrm{ml}$ streptomycin, and were incubated at $37^{\circ} \mathrm{C}$ with $5 \% \mathrm{CO}_{2}$.

\section{Western blot analysis}

The cells were harvested with $0.02 \%$ EDTA and 0.025\% trypsin, rinsed three times in phosphate-buffered saline (PBS), and pelleted in $1.5 \mathrm{ml}$ microcentrifugetubes by centrifugation. Whole-cell extracts were prepared with the Nuclear Extract Kit (Active Motif, Carlsbad, California, USA). The protein content of the cell lysate was determined by using the Bradford calorimetric assay method (Bio-Rad, Richmond, California, USA). Fifty $\mu \mathrm{g}$ of cell lysates were directly resolved by $12 \%$ SDS-PAGE and were transferred to PVDF membranes (Millipore, MA, USA). Proteins transferred to the membrane were detected by GAPDH and PDCD6 (Abcam Inc, MA, USA) primary antibodies and horseradish peroxidaselinked secondary antibodies (anti-rabbit IgG), and the proteins were then visualized by enhanced chemiluminescence reagents. BioRad Laboratories Quantity One software (BioRad, CA, USA) was used to quantify the blots, GAPDH as a loading control.

\section{Quantitative real-time polymerase chain reaction (qRT- PCR)}

RNeasy Mini Kits (QIAGEN Inc., Valencia, CA) were used to extract total RNA from cells and tissue. RNA (5 ng) was reverse transcribed to cDNA using a SuperScript First-Strand Synthesis System for RT-PCR (Invitrogen Corp., Carlsbad, CA). Quantitative real-time PCR was performed to determine the expression level of $P D C D 6$ mRNA in each tumor sample, using GAPDH as an endogenous control for calibration. The primer sequences were designed online (http://www.idtdna. com) and ordered from Invitrogen Corp. (Shanghai, China). The primer sequences were: TGA CCA GTT CCA CGA CAT CCT CAT (PDCD6 forward), TTG GCT CTT TCC ATG TTG TGC TGC (PDCD6 reverse), GAA GGT GAA GGT CGG AGT C (GAPDH forward), and GAA GAT GGT GAT GGG ATT TC (GAPDH reverse). Quantitative real time PCR was carried out using an ABI 7500 real-time PCR system (Applied Biosystems Inc., Foster City, CA, USA). The PCR reaction solution $(25 \mu \mathrm{l})$ contained $5 \mathrm{ng} / \mu \mathrm{l} \mathrm{cDNA}$, $12.5 \mu$ l Power SYBR Green PCR Master Mix (Bioer Technology Inc., Hangzhou, China) and a pair of primers at a final concentration of $5 \mu \mathrm{M}$ for PDCD6 and $G A P D H$. Dissociation curve analysis was performed after PCR to confirm the size of PCR products. All tumor samples were analyzed in duplicate along with negative controls. Real-time PCR results were recorded as Ct values (threshold cycle). To adjust for the total amount of cDNA used for analysis in each sample, a $\Delta$ Ct was calculated based on the difference in $\mathrm{Ct}$ values between the target gene PDCD6 and the housekeeping gene GAPDH. $\triangle \mathrm{Ct}$ was further converted to an expression index (EI) based on the formula $2^{(-\Delta C t)}$. Inhibition rate of PDCD6 was calculated by formula $\left[1-2^{(-\Delta \Delta \mathrm{Ct})}\right] * 100 \%$.

\section{Transfection of lentiviral vectors with shRNA for PDCD6}

The pGCSIL-GFP-shRNA-PDCD6 lentiviral vectors (pGCSIL, a lentiviral vector) were purchased from Shanghai GeneChem Company and the target shRNA sequences as follows: 5'- cagagggtcgataaagaca-3'. pGCSIL-GFP-lentiviral vector was used as a control. The lentiviral vectors and pHelper were co-transfected into $293 \mathrm{~T}$ cells. The culture supernatants were collected, concentrated, and used as a virus stock. HO8910 PM at 40\%-50\% confluence was inflected with lentivirus expression shRNA to the human PDCD6 gene or vector control. The shRNA targeting sequences was validated for the most efficient interference of PDCD6 by qRT-PCR and Immunoblotting.

\section{Cell proliferation assay}

To assess cell proliferation effected by PDCD6, HO8910 PM cells was infected with shRNA-PDCD6 for 72 $\mathrm{h}$. Then the cells were plated at $5 \times 10^{3}$ cells/well in 96well microtiter plates and cultured at $37^{\circ} \mathrm{C}$ with $5 \%$ $\mathrm{CO}_{2}$. Each $24 \mathrm{~h}$, the cell viability was measured by MTT (3-[4,5-dimethylthiazol-2-yl]-2,5 diphenyl tetrazolium bromide) reagent (Sigma, St Louis, MO, USA) according to the manufacturer's instructions. Briefly, add reconstituted MTT in an amount equal to $10 \%$ of the culture medium volume. Return to incubator for $2 \mathrm{~h}$. After that, medium was moved, and MTT formazan was resolved 
in $100 \mathrm{ul}$ acidic isopropanol. Absorbance was measured at a wavelength of $570 \mathrm{~nm}$. Experiments were performed in triplicate, and 3 different experiments were performed for each experimental condition. A cell proliferation curve was constructed by measuring cell growth for 4 consecutive days.

\section{Cell cycle assay}

Cell cycle distribution was monitored by flow cytometry (FACSCalibur, Becton Dickinson, Franklin Lakes, NJ, USA) using propidium iodine (PI) staining (Becton Dickinson) according to the protocol of the manufacturer. Briefly, the H0-8910 PM cells which were preinfected with shRNA-PDCD6 for $72 \mathrm{~h}$ were plated in 6well plates. After cultured for $48 \mathrm{~h}$, cells were collected, washed with PBS, and fixed with $2 \%$ paraformaldehyde at room temperature for $30 \mathrm{~min}$. After paraformaldehyde was moved, cell pellets were resuspended by $70 \%$ ethanol and stored at $-20^{\circ} \mathrm{C}$ for $2 \mathrm{~h}$. Then spin cells out of fix, pellets were resuspend in PBS with $200 \mathrm{ug} / \mathrm{ml}$ RnaseA and incubated at $37^{\circ} \mathrm{C}$ for $1 \mathrm{~h}$. Added PI to a final concentration of $50 \mathrm{ug} / \mathrm{ml}$ for $2 \mathrm{~h}$ before analyzing on the flow cytometer.

Software-based cell cycle analysis was performed using ModFit 2.0 (Verity, Topsham, ME).

\section{Hoechst stain for detecting apoptotic cells}

Apoptotic cells were detected by fluorescence imaging using Hoechst 33258 stain (Sigma-Aldrich, St. Louis, MO, USA). Seventy-two hours after transfection, cells were washed twice with PBS, and then incubated with Hoechst reagent $(10 \mathrm{mg} / \mathrm{ml})$ for $30-45 \mathrm{~min}$ at $37^{\circ} \mathrm{C}$ in the dark. Morphological changes including a reduction in volume and nuclear chromatin condensation were observed under a fluorescence microscope (Nikon, Tokyo, Japan) and photographed at a magnification of $200 \times$. Apoptotic cells were counted in at least three to four random fields and expressed as percentage of total cells.

\section{Transwell migration and invasion assay}

For transwell migration assays, cells were plated in the top chamber with the non-coated membrane (24-well insert; pore size, $8 \mathrm{~mm}$; BD Biosciences). For invasion assays, cells were plated in the top chamber with Matrigel-coated membrane (24-well insert; pore size, $8 \mathrm{~mm}$; BD Biosciences). In both assays, a number of $2 \times 10^{5}$ HO-8910 PM cells treatment in $100 \mu \mathrm{L}$ serum-free medium were pre-infected with shRNA-PDCD6 for $72 \mathrm{~h}$ and added to the upper chamber, while $500 \mu \mathrm{L}$ medium with 10\% FBS were added to the lower chamber. Transwells were incubated for $24 \mathrm{~h}$ at $37^{\circ} \mathrm{C}$. Cells on the inside of the transwell inserts were removed with a cotton swab, and cells on the underside of the insert filter were fixed and stained. Photographs of four random fields were taken, and the cells were counted to calculate the average number of cells that had transmigrated.

\section{Patients and follow-up}

Patient samples of ovarian cancer were consecutively collected in the Gynecologic Oncology Unit at University of Turin in Italy between October 1991 and February 2000 and all participants gave informed consent. Use of tissue samples was approved with an Ethical Review Committee of University. All ovarian cancer tissues were obtained at the time of cytoreductive surgery. In this study, we identified 212 patients with primary epithelial ovarian cancer who underwent cytoreductive surgery. The average patient age at surgery was 57.6 years (SD, 11.5; range, 26-82). Follow-up information was available for 203 patients who were followed from surgery to June 2001. The overall follow-up time ranged from 0.6 to 114 months, and the median was 31 months. The median disease progression-free survival was 20.6 months. Disease staging was classified according to the criteria of FIGO (the International Federation of Gynecologists and Obstetricians)[11]. Of the 211 patients with information on disease stage, 51 (24.2\%) were diagnosed with stage I disease, 12 (5.7\%) were stage II, 133 (63.0\%) were stage III, and 15 (7.1\%) were stage IV. Histological type determined following the World Health Organization (WHO) criteria [12] included serous, endometrioid, mucinous, clear cell, and other epithelial tumors. For data analysis, tumor histotypes were grouped into non-serous $(59.9 \%, \mathrm{n}=127)$ and serous $(40.1 \%, \mathrm{n}=85)$. Of the 211 patients with information on tumor grade, most patients $(65.4 \%, \mathrm{n}=$ 138 ) had grade 3 tumors (poorly differentiated); few had grade 1 or $2(34.6 \%, n=73)$. After surgery, most of the patients were treated with platinum-based chemotherapy following a standard protocol.

\section{Statistical analysis}

The data from in vitro experiments were expressed as the mean \pm SD for 3 independent experiments using three difference preparations. The difference between the means was assessed by Student's $t$-test. For patient study, PDCD6 mRNA expression was analyzed as a continuous variable and as a categorical variable after grouping by expression index (EI) distribution as low expression (EI < 0.1), middle expression (EI 0.1-1) and high expression (EI $>1)$. Associations between PCDC6 expression and clinical variables were analyzed using the Chi-square test. Survival analysis was performed for progression-free and overall survival using the Cox proportional hazards regression and Kaplan-Meier curves. All $p$-values were two-sided, and a probability of 0.05 or smaller was considered statistical significance. SPSS 
version 11.0 (SPSS Inc., Chicago, IL) was used for data analysis.

\section{Results}

Expression of PDCD6 in ovarian cancer cell lines with different metastatic potential

To confirm our previous proteomic results [6], we compared the expression of PDCD6 in H0-8910 and H08910 PM cells by western blot. The results showed that PDCD6 expression was higher in H0-8910 PM than that in $\mathrm{H0}-8910$ (Figure 1A).

\section{Knockdown of PDCD6 in HO-8910 PM cells by lentiviral vectors-mediated transfection}

In the present study, lentiviral vectors-mediated transfection was used to determine effects of $P D C D 6$ expression silencing on metastatic ovarian cancer cell behavior. Seventy two hours after transfection, HO-8910 PM cells were observed using a fluorescent microscope. The transfection efficiency was evaluated by counting the green fluorescent cells, which was over $95 \%$ when the cells were infected with a multiplicity of infection (MOI) of 3. mRNA and protein levels of PDCD6 were detected by RT-PCR and Western blot at $72 \mathrm{~h}$ after transfection. The results showed pGCSIL-GFP-shRNAPDCD6 lentiviral vector was effective in silencing PDCD6 expression and the inhibition rate of PDCD6 was about $80 \%$ (Figure 1B-C).

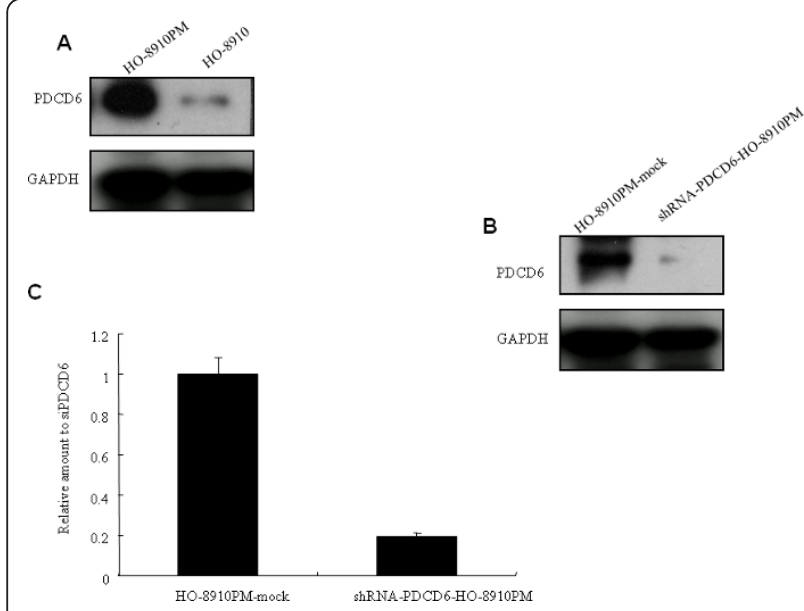

Figure 1 A. Western blotting analysis showed protein expression of PDCD6 was higher in HO-8910 PM cells than that in HO-8910 cells. GAPDH was used as a loading control. B. Western blotting analysis showed protein expression of PDCD6 in shRNA-PDCD6-HO-8910 PM was decreased compared with that in control HO-8910 PM-mock. GAPDH was used as a loading control. C. qRT-PCR results showed mRNA expression of PDCD6 in shRNAPDCD6-HO-8910 PM was inhibited by $80 \%$ compared with that in HO-8910 PM-mock.
Influence of HO-8910 PM cell proliferation, apoptosis and cell cycle by PDCD6 expression silencing in vitro As shown in Figure 2, PDCD6 knockdown had no obvious effect on cell proliferation and apoptosis although apoptotic cells were increased slightly and cell growth slowed down a little bit in HO-8910 PM cells infected with shRNA-PDCD6. No significant difference of cell cycle distribution was found.

Inhibition of HO-8910 PM migration and invasion in vitro by siRNA-mediated PDCD6 knockdown

Migration and invasion assay in vitro were carried out to evaluate PDCD6 knockdown on HO-8910 PM cell motility. The result showed that the average number of migrated and invaded HO-8910 PM cells transfected with siRNA significantly decreased in comparison with the Mock group, $p<0.001$ and $P=0.050$ respectively (Figure 3).

\section{Correlation of PDCD6 mRNA expression with disease} characteristics and patient survival

Spearman correlation analysis showed PDCD6 expression was positively correlate with residual tumor size ( $\mathrm{r}$ $=0.16, p=0.019)$ (Table 1). Compared the median expressions of PDCD 6 by different clinical and pathologic characteristics, no significant difference was found, although PDCD6 expression was slight higher in advanced (stagesIII and IV) than that in early disease

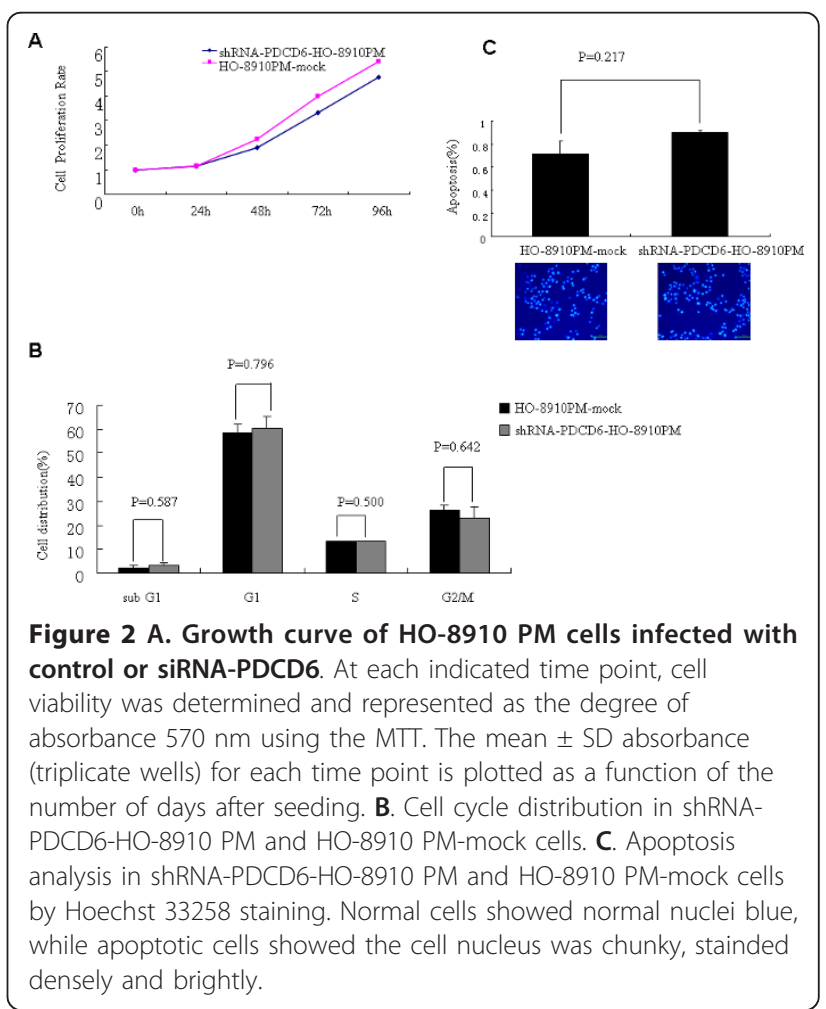




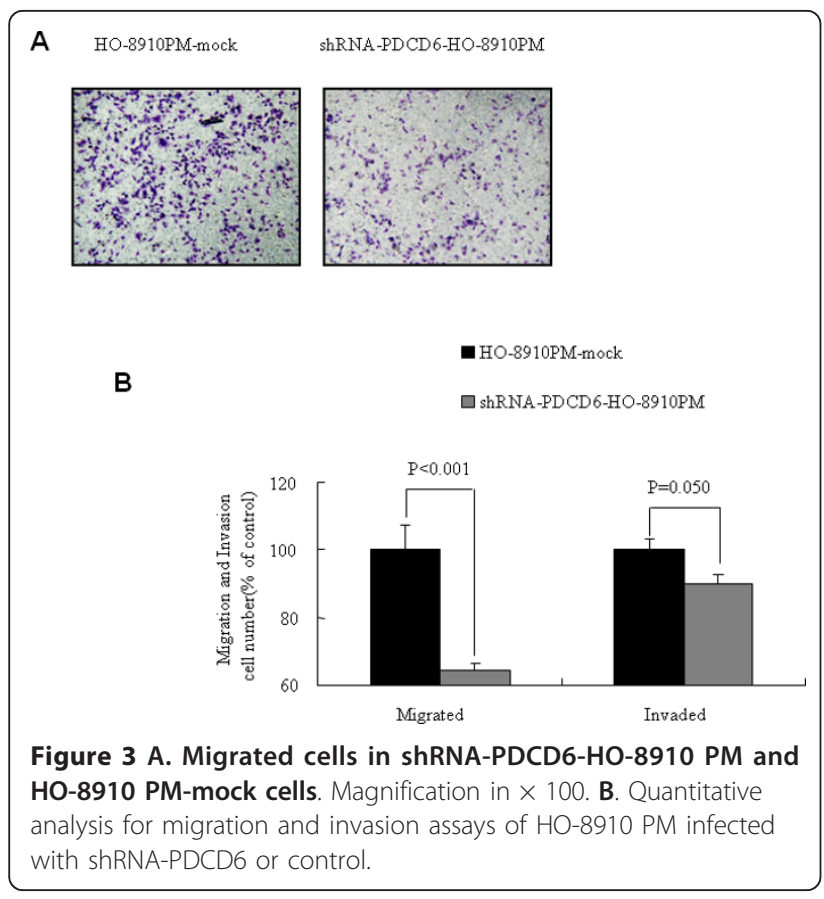

(stages I and II), 0.28 versus $0.16, p=0.183$, and in poorly differentiated tumors (grade3) than in well-differentiated tumors (grade 1 or 2), 0.29 versus $0.16, p=$ 0.275 . Patients who had residual tumor after surgery had higher PDCD6 expression than patients who had no residual tumor, 0.31 versus $0.18, p=0.261$ (Table 2). Similar results were found when categorical variable was analyzed (Table 2), but significant difference of $P D C D 6$ expression was showed between the patients with residual tumor and without residual tumor after surgery. Patients with residual tumor had significantly higher PDCD6 expression than patients who had no residual tumor $(29.3 \%$ versus $16.7 \%, P=0.050)$.

PDCD6 mRNA expression was significantly associated with progression free survival (Table 3). Patients with medium or high levels of PDCD6 mRNA were at higher risk for disease progression, compared to those with low levels (HR, 1.29; $P=0.024$ for mid levels; and $H R, 1.57$;

Table 1 Spearman correlation of PDCD6 mRNA expressions with clinicopathologic features of ovarian cancer

\begin{tabular}{lc}
\hline Variable & PDCD6 mRNA expression \\
\cline { 2 - 2 } & correlation coefficient $(\boldsymbol{P})$ \\
\hline Age $(n=209)$ & $-0.03(0.642)$ \\
\hline Disease stage $(n=211)$ & $0.07(0.310)$ \\
\hline Tumor grade $(n=211)$ & $0.02(0.748)$ \\
\hline Tumor histology $(n=212)$ & $0.00(0.954)$ \\
\hline Residual tumor size $(n=206)$ & $\mathbf{0 . 1 6 ( 0 . 0 1 9})^{\mathbf{a}}$ \\
\hline
\end{tabular}

${ }^{a}$ Bold values are statistically significant $(p<0.05)$
$P=0.045$ for high levels) after adjusting for age, disease stage, tumor grade, histologic type and residual tumor size. Kaplan-Meier survival analysis demonstrates similar results. Patients who had medium or high PDCD6 mRNA had worse progression free survival (Figure 4). No significant association was found between PDCD6 mRNA expression and overall survival although patients with medium or high levels of PDCD6 mRNA were at higher risk for death compared to those with low level.

\section{Discussion}

In our proteomic analysis of ovarian cancer cell lines, we detected 21 significantly different spots (two-fold increase or decrease) through 2-D gel electrophoresis, of which 17 candidate proteins were successfully identified and characterized. These proteins were mainly involved in the regulation of cell growth, proliferation, motility, apoptosis and tumor immunity [6]. To further study the function of those differentially expression proteins in ovarian cancer, in this study, we selected PDCD6, which had the highest protein score and $100 \%$ protein confidence interval [6]. As expected, PDCD6 overexpression in HO-8910 PM as compared to HO-8910 was confirmed by western blot analysis.

PDCD6, discovered by cDNA library screening for apoptosis-related genes [13], is a calcium binding protein which belongs to the penta-EF-Hand family that has the Ca2 + -binding helix-loop-helix structures [14]. PDCD6 functions as a Ca2+ sensor by changing its conformation [15]. This conformational change enables PDCD6 to interact with various intracellular proteins containing Pro-rich regions in a $\mathrm{Ca} 2+$-dependent manner, such as Alix (ALG-2-interacting protein X)[16], annexins VII, XI [17], Sec31A (SEC31 homolog A)[18], and TSG101 (tumor susceptibility gene 101)[16]. Original cloning report of PDCD6 cDNA in a screen for genes involved in apoptosis [13] and early studies indicated PDCD6 participates in T cell receptor-induced programmed cell death in a $\mathrm{Ca} 2+$-dependent manner as a pro-apoptotic factor [19]. Recent study showed Alix and ALG-2 involved in tumor necrosis factor receptor 1-induced cell death by interacting with procaspase-8 [20]. However, apoptosis was not blocked in PDCD6 deficient mice, suggesting that PDCD6 is functionally redundant [21]. Furthermore, PDCD6 was found to be up-regulated in a variety of human tumors compared to normal tissues of the breast, liver, lung, and colon, especially in metastatic tissues, which suggests that in addition to its known pro-apoptotic function PDCD6 may play a role in cell survival [22-24]. Additionally, in vitro experiments indicated that PDCD6 had an anti-apoptotic action in HeLa cells via facilitating proliferating cells passing through the G2/M cell cycle checkpoints [25]. 
Table 2 Association of PDCD6 mRNA expression with clinical and pathological characteristics of ovarian cancer

\begin{tabular}{|c|c|c|c|c|c|c|c|}
\hline \multirow[b]{2}{*}{ Variable } & \multirow[b]{2}{*}{$\mathrm{n}$} & \multicolumn{6}{|c|}{ PDCD6 Expression } \\
\hline & & Median (5th-95th) & $p$-value ${ }^{b}$ & Low $^{c}$ & Middle $^{d}$ & $\mathrm{High}^{\mathrm{e}}$ & $p$-value ${ }^{f}$ \\
\hline$\underline{\text { Stage }}$ & 211 & & & n (\%) & n (\%) & n (\%) & \\
\hline$|-| \mid$ & 63 & $0.16(0-4.78)$ & 0.183 & $25(39.7)$ & $28(44.4)$ & 10(15.9) & 0.256 \\
\hline III-IV & 148 & $0.28(0-5.26)$ & & $52(35.1)$ & 57(38.5) & $85(26.4)$ & \\
\hline Grade & 211 & & & & & & \\
\hline $1 \sim 2$ & 73 & $0.16(0-4.41)$ & 0.275 & $26(35.6)$ & $33(45.2)$ & 14(19.2) & 0.477 \\
\hline 3 & 138 & $0.29(0-5.53)$ & & $51(37.0)$ & $52(37.7)$ & $35(25.4)$ & \\
\hline Histology & 212 & & & & & & \\
\hline Non-Serous & 127 & $0.20(0-5.03)$ & 0.321 & $47(37.0)$ & $53(41.7)$ & $27(21.3)$ & 0.734 \\
\hline Serous & 85 & $0.28(0-5.41)$ & & $30(35.3)$ & 33(38.8) & $22(25.9)$ & \\
\hline Residual Tumor & 206 & & & & & & \\
\hline No Residual & 90 & $0.18(0-3.69)$ & 0.261 & $32(35.6)$ & $43(47.8)$ & $15(16.7)$ & $0.050^{h}$ \\
\hline Residual & 116 & $0.31(0-7.20)$ & & $43(37.1)$ & 39(33.6) & $34(29.3)$ & \\
\hline
\end{tabular}

${ }^{a}$ Expression levels at the 5th and 95th percentiles; ${ }^{\mathrm{b}}$ Wilcoxon two-sample test with $\mathrm{t}$ approximation; ${ }^{\mathrm{c}}$ Low: Expression Index (EI) < 0.1;

${ }^{\mathrm{d}}$ Middle: Expression Index (EI) 0.1-1; ${ }^{\mathrm{e}}$ High: Expression Index (EI) $>1 ;{ }^{\mathrm{f}} p$-value from Chi-square test;

${ }^{g} p$-value from Spearman correlation test; ${ }^{\text {h }}$ Bold values are statistically significant $(p<0.05)$

Different from the previous study, PDCD6 knockdown had no obvious effect on cell proliferation and apoptosis although apoptotic cells were increased slightly and cell growth slowed down a little bit in HO-8910 PM cells infected with shRNA-PDCD6, but did result in decrease in cell motility and invasiveness. These results indicated that over expression of PDCD6 promote both migration and invasion in ovarian cancer cells.

Significantly, our patient study supported the results in vitro. PDCD6 mRNA expression was significantly

Table 3 Associations of PDCD6 mRNA expression and patient survival $^{\mathrm{a}}$

\begin{tabular}{|c|c|c|c|c|c|c|}
\hline & $\begin{array}{l}\text { Crude } \\
\text { HR }\end{array}$ & $\begin{array}{l}95 \% \\
\mathrm{Cl}^{\mathbf{b}}\end{array}$ & $\begin{array}{l}p- \\
\text { value }\end{array}$ & $\begin{array}{l}\text { Adjust } \\
\text { HR }\end{array}$ & $95 \% \mathrm{Cl}$ & $\begin{array}{l}p \text { - } \\
\text { value }\end{array}$ \\
\hline \multicolumn{7}{|c|}{ Disease-Free Survival $^{c}$} \\
\hline $\begin{array}{l}\text { Low } \\
\text { PDCD6 }\end{array}$ & 1 & & & 1 & & \\
\hline Mid PDCD6 & 1.65 & $\begin{array}{l}1.01- \\
2.70\end{array}$ & 0.046 & 1.29 & $\begin{array}{l}1.08- \\
2.91\end{array}$ & 0.024 \\
\hline $\begin{array}{l}\text { High } \\
\text { PDCD6 }\end{array}$ & 1.87 & $\begin{array}{l}1.09- \\
3.21\end{array}$ & 0.023 & 1.57 & $\begin{array}{l}1.09- \\
2.58\end{array}$ & 0.045 \\
\hline \multicolumn{7}{|c|}{ Overall Survival $^{d}$} \\
\hline $\begin{array}{l}\text { Low } \\
\text { PDCD6 }\end{array}$ & 1 & & & 1 & & \\
\hline Mid PDCD6 & 1.51 & $\begin{array}{l}0.93- \\
2.43\end{array}$ & 0.094 & 1.88 & $\begin{array}{l}0.95- \\
3.08\end{array}$ & 0.092 \\
\hline $\begin{array}{l}\text { High } \\
\text { PDCD6 }\end{array}$ & 1.13 & $\begin{array}{l}0.64- \\
1.99\end{array}$ & 0.664 & 1.07 & $\begin{array}{l}0.61- \\
1.91\end{array}$ & 0.801 \\
\hline
\end{tabular}

${ }^{a}$ Associations determined by Cox proportional hazards regression and adjusted for age, stage, grade, histotype and residual tumor size. Significance level of $p=0.05$

b $95 \%$ Wald Confidence Limits

c Hazard Ratio (HR) for relapse with respect to low PDCD6 expression

${ }^{\mathrm{d}}$ Hazard Ratio (HR) for death with respect to low PDCD6 expression correlated with residual tumor size. Patients with residual tumor had higher PDCD6 expression than patients with no residual tumor. Furthermore, PDCD6 expression was associated with patient survival; patients with high PDCD6 mRNA had shorter disease progressionfree survival than those with middle or low expression. Our findings suggest that PDCD6 mRNA expression is an independent predictor of ovarian cancer progression free survival.

In the study, we found that high PDCD6 expression was associated with disease progression, but not death. There are a number of possible reasons that may explain this discrepancy. First, PDCD6 may promote disease progression or reduce the effect of adjuvant treatment by stimulating tumor cell migration or invasion, but these effects do not lead to the death of all cases. Some patients may die of other reasons. Second, the study was relatively small and the follow-up time

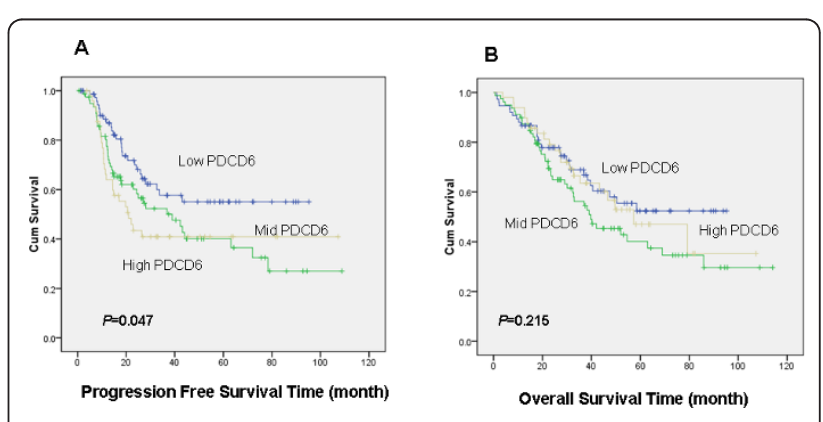

Figure 4 Kaplan-Meier progression-free survival curves $(A)$ and overall survival curves (B) according to PDCD6 levels: Among the patients, 77 patients had low PDCD6 expression, 86 patients had medium PDCD6 expression, and 49 patients had high PDCD6 expression. 
was short. We do not have enough power to find a significant association with overall survival. Third, our study findings are still preliminary. Independent large studies are needed to confirm these results.

These findings may be explained by our observations in vitro and vivo which are generally in agreement with the findings of other studies. One study of lung cancer demonstrated that PDCD6 overexpression was indicative of unfavorable prognosis for patients with early stage non-small cell lung cancer or lung adenocarcinoma; the protein may serve as a potential molecular marker for aggressive lung cancer [23]. However, no association was found between PDCD6 protein expression measured by immunohistochemical staining and survival of lung, breast or colon cancer patients [26]. And recent study reported that purified recombinant human PDCD6 inhibits vascular endothelial growth factor (VEGF)-induced proliferation, invasion, and capillary-like structure tube formation in vitro through PI3K/mTOR/p70S6K pathway by interacting of VEGFR-2 [27]. Those inconsistent findings in the literature may be due to the observations made on different cancer cell lines or disease stages. In early stage tumors or tumors other than ovarian cancer, PDCD6 may have a pro-apoptotic effect on the tumors, whereas in our case when the tumor is ovarian cancer or tumors progress to advanced stages (since most of ovarian cancers are grade 3 tumors), the PDCD6 function changes to an opposite direction either due to different regulation or downstream targets, which is anti-apoptotic or pro-migration that leads to shortened progression-free survival.

In the future, we will continue this work from clinic to confirm its prognostic utility as well as from lab experiment to elucidate its molecular mechanism, finding or assembling another clinical study to measure PDCD6 expression in ovarian tumors and to analyze its association with disease progression and overall survival, performing chip assay to identify upstream modulators of PDCD6 as well as its downstream targets or pathways being involved in the PDCD6's effect on tumor progression. With a comprehensive understanding of PDCD6 regulation and function, we may be able to tell what confounding biology is involved in the relationship between PDCD6 expression and ovarian cancer progression.

\section{Conclusions}

In summary, PDCD6 was identified and characterized as differentially expressed proteins between ovarian cancer cells with low and high metastatic property by our previous comparative proteomic study. It was further confirmed to be overexpressed in HO-8910 PM as compared to HO-8910 by western blot. PDCD6 knockdown significantly inhibited migration and invasion of ovarian cancer cells in vitro, supporting the notion that PDCD6 played an important role in ovarian cancer progression. PDCD6 mRNA was detectable in most of ovarian tumor samples, and the expression was correlated with residual tumor size. High PDCD6 expression was found to be associated with unfavorable prognosis of the disease. It may serve as an independent marker for ovarian cancer prognosis. Further studies are needed to more completely elucidate the molecular mechanisms of PDCD6 in ovarian cancer progression.

\section{Acknowledgements}

The study was supported by the National Natural Science Foundation (Number 30471819) and National Natural Science Young Foundation (Number 81101986). Dionyssios Katsaros is partially supported by Regione Piemonte Grant, Progetto Ricerca Sanitaria Finalizzata 2008. We gratefully thank Dr. Lei Xiong for his valuable suggestion.

\section{Author details}

${ }^{1}$ Center for Genetic and Genomic Medicine, School of Medicine, Zhejiang University, Hangzhou, Zhejiang, China. ${ }^{2}$ Cancer Research Institute, Zhejiang Cancer Hospital, Hangzhou, Zhejiang, China. ${ }^{3}$ Department of Obstetrics and Gynecology, Gynecologic Oncology and Breast Cancer Unit, University of Turin, Turin, Italy. ${ }^{4}$ Departments of Epidemiology and Public Health, Yale Cancer Center, Yale University School of Medicine, New Haven, CT, USA. ${ }^{5}$ Department of Pathology and Laboratory Medicine, University of Rochester, Rochester, NY, USA.

\section{Authors' contributions}

XHY, FJG and GLH carried out the cell assay; YLS and GY carried out western blot and RT-PCR assay; SD, KD and YH carried out the case collection; and SD and XHY analyzed the results.XSH and QM conceived the study, participated in the design, and coordinated and helped draft the manuscript. All authors read and approved the final manuscript.

\section{Competing interests}

The authors declare that they have no competing interests.

Received: 30 November 2011 Accepted: 27 February 2012

Published: 27 February 2012

\section{References}

1. Jemal A, Siegel R, Ward E, Hao Y, Xu J, Murray T, Thun MJ: Cancer Statistics, 2008. CA Cancer J Clin 2008, 58:71-96.

2. du Bois A, Luck HJ, Meier W, Mobus V, Costa S, Richter B, Bauknecht T, Warm M, Schroeder W, Olbricht S: Carboplatin plus paclitaxel as first-line chemotherapy in previously untreated advanced ovarian cancer. German AGO Study Group Ovarian Cancer. Arbeitsgemeinschaft Gynakologische Onkologie. Semin Oncol 1997, 24:28-S11.

3. Aravantinos G, Fountzilas G, Kosmidis P, Dimopoulos MA, Stathopoulos GP, Pavlidis N, Bafaloukos D, Papadimitriou C, Karpathios S, Georgoulias V: Paclitaxel plus carboplatin versus paclitaxel plus alternating carboplatin and cisplatin for initial treatment of advanced ovarian cancer: long-term efficacy results: a Hellenic Cooperative Oncology Group (HeCOG) study. Ann Oncol 2005, 16:1116-1122.

4. Shenhua X, Hanzhou M, Lijuan Q, Yongzhen S, Chihong Z, Xiaoshu H, Yongliang G, Shanzing D: Establishment and Characterization of a Model of Highly Metastasizing Human Ovarian Cancer Transplanted into Subcutis of the Nude Mice. J Exp Clin Cancer Res 1995, 14:387-394.

5. Shenhua X, Lijuan Q, Hanzhou N, Xinghao N, Chihong Z, Gu Z, Weifang D, Yongliang G: Establishment of a highly metastatic human ovarian cancer cell line (HO-8910 PM) and its characterization. J Exp Clin Cancer Res 1999, 18:233-239.

6. Su D, Xu SH, Gu LH: Comparative proteomics analysis of differentially expressed metastasis-associated proteins in human ovarian cancer cell lines. Zhonghua Fu Chan Ke Za Zhi 2005, 40:619-622. 
7. Jung YS, Kim KS, Dong Kim K, Lim JS, Kim JW, Kim E: Apoptosis-Linked Gene 2 Binds to the Death Domain of Fas and Dissociates from Fas during Fas-Mediated Apoptosis in Jurkat Cells. Biochem Biophys Res Commun 2001, 288:420-426.

8. Shibata H, Yamada K, Mizuno T, Yorikawa C, Takahashi H, Satoh H, Kitaura Y, Maki M: The Penta-EF-Hand Protein ALG-2 Interacts with a Region Containing PxY Repeats in Alix/AIP1, Which Is Required for the Subcellular Punctate Distribution of the Amino-Terminal Truncation Form of Alix/AIP1. J Biochem 2004, 135:117.

9. Jang IK, Hu R, Lacana E, D’Adamio L, Gu H: Apoptosis-Linked Gene 2Deficient Mice Exhibit Normal T-Cell Development and Function. Mol Cell Biol 2002, 22:4094-4100.

10. la Cour JM, Mollerup J, Winding P, Tarabykina S, Sehested M, Berchtold MW: Up-Regulation of ALG-2 in Hepatomas and Lung Cancer Tissue. Am J Pathol 2003, 163:81-89.

11. Shepherd JH: Revised FIGO staging for gynaecological cancer. BJOG: An Int J Obstetrics Gynaecology 1989, 96:889-892.

12. Scully RE, Sobin LH: Histologic typing of ovarian tumors. Arch Pathol Lab Med 1987, 111:794-795.

13. Vito $P$, Lacana $E$, D'Adamio L: Interfering with apoptosis: $\mathrm{Ca}(2+)$-binding protein ALG-2 and Alzheimer's disease gene ALG-3. Science 1996, 271:521-525.

14. Maki M, Narayana SV, Hitomi K: A growing family of the Ca2 + -binding proteins with five EF-hand motifs. Biochem J 1997, 328(Pt 2):718-720.

15. Maki M, Yamaguchi K, Kitaura Y, Satoh H, Hitomi K: Calcium-induced exposure of a hydrophobic surface of mouse ALG-2, which is a member of the penta-EF-hand protein family. J Biochem 1998, 124:1170-1177.

16. Suzuki H, Kawasaki M, Inuzuka T, Okumura M, Kakiuchi T, Shibata H, Wakatsuki S, Maki M: The mechanism of Ca2 + -dependent recognition of Alix by ALG-2: insights from X-ray crystal structures. Biochem Soc Trans 2009, 37:190-194.

17. Satoh H, Nakano $Y$, Shibata H, Maki M: The penta-EF-hand domain of ALG-2 interacts with amino-terminal domains of both annexin VII and annexin XI in a Ca2 + -dependent manner. Biochim Biophys Acta 2002, 1600:61-67.

18. Shibata H, Suzuki H, Yoshida H, Maki M: ALG-2 directly binds Sec31A and localizes at endoplasmic reticulum exit sites in a Ca2 + -dependent manner. Biochem Biophys Res Commun 2007, 353:756-763.

19. D'Adamio L, Lacana E, Vito P: Functional cloning of genes involved in Tcell receptor-induced programmed cell death. Semin Immunol 1997, 9:17-23.

20. Mahul-Mellier AL, Strappazzon F, Petiot A, Chatellard-Causse C, Torch S, Blot B, Freeman K, Kuhn L, Garin J, Verna JM: Alix and ALG-2 Are Involved in Tumor Necrosis Factor Receptor 1-induced Cell Death. J Biol Chem 2008, 283:34954.

21. Jang IK, Hu R, Lacana E, D'Adamio L, Gu H: Apoptosis-linked gene 2deficient mice exhibit normal T-cell development and function. Mol Cell Biol 2002, 22:4094-4100.

22. la Cour JM, Mollerup J, Winding P, Tarabykina S, Sehested M, Berchtold MW: Up-regulation of ALG-2 in hepatomas and lung cancer tissue. Am J Pathol 2003, 163:81-89.

23. Aviel-Ronen S, Coe BP, Lau SK: da Cunha Santos G, Zhu CQ, Strumpf D, Jurisica I, Lam WL, Tsao MS: Genomic markers for malignant progression in pulmonary adenocarcinoma with bronchioloalveolar features. Proc Natl Acad Sci USA 2008, 105:10155-10160.

24. la Cour JM, Hj BR, Mollerup J, Simon R, Sauter G, Berchtold MW: The apoptosis linked gene ALG-2 is dysregulated in tumors of various origin and contributes to cancer cell viability. Molecular Oncology 2008, 1:431-439.

25. Hoj BR, la Cour JM, Mollerup J, Berchtold MW: ALG-2 knockdown in HeLa cells results in G2/M cell cycle phase accumulation and cell death. Biochem Biophys Res Commun 2009, 378:145-148.

26. la Cour JM, Hoj BR, Mollerup J, Simon R, Sauter G, Berchtold MW: The apoptosis linked gene ALG-2 is dysregulated in tumors of various origin and contributes to cancer cell viability. Mol Oncol 2008, 1:431-439.

27. Rho SB, Song YJ, Lim MC, Lee SH, Kim BR, Park SY: Programmed cell death 6 (PDCD6) inhibits angiogenesis through $\mathrm{PI3K} / \mathrm{mTOR} / \mathrm{p} 70 \mathrm{~S} 6 \mathrm{~K}$ pathway by interacting of VEGFR-2. Cell Signal 2012, 24:131-139. doi:10.1186/1479-5876-10-31

Cite this article as: Su et al:: PDCD6 is an independent predictor of progression free survival in epithelial ovarian cancer. Journal of Translational Medicine 2012 10:31.

\section{Submit your next manuscript to BioMed Central and take full advantage of:}

- Convenient online submission

- Thorough peer review

- No space constraints or color figure charges

- Immediate publication on acceptance

- Inclusion in PubMed, CAS, Scopus and Google Scholar

- Research which is freely available for redistribution

Submit your manuscript at www.biomedcentral.com/submit
C) Biomed Central 